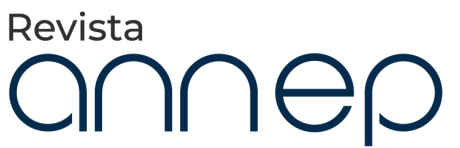

de Direito Processual

\title{
Case Management no Brasil
}

\author{
Case management in Brazil
}

Trícia Navarro Xavier Cabral'

\section{Resumo}

O presente estudo objetiva identificar como o case management se desenvolve no direito brasileiro, por meio de uma avaliação do nosso formato de processo civil, das principais técnicas processuais que garantem o bom gerenciamento do processo, e, ainda, a performance do juiz frente aos novos institutos do Código de Processo Civil.

Palavras-chave: Case management; Direito brasileiro; Técnicas processuais

\section{Abstract}

This study aims to identify how case management develops in Brazilian law, through an evaluation of our civil procedure format, the main procedural techniques that ensure the proper management of the process, and also the performance of the judge in front of the new institutes of the Code of Civil Procedure.

Keywords: Case management; Brazilian law; Procedural techniques.

\section{Case management no Brasil}

Case management representa a adoção de uma conduta gerencial pelo juiz, capaz de promover maior racionalidade e efetividade ao processo judicial. Trata-se de uma nova postura que reflete mudanças ideológicas e comportamentais, em prol de uma prestação jurisdicional mais adequada e eficiente.

A atuação passiva do juiz, que apenas conduzia o processo sem maiores ingerências no procedimento, foi substituída por uma atitude mais proativa, com maior comprometimento e responsabilidade no alcance de celeridade e dos resultados satisfatórios da jurisdição. Não obstante, os poderes gerenciais do juiz em relação à duração do processo e às técnicas aplicáveis também proporcionaram um maior equilíbrio, lealdade e cooperação na relação processual. 
Os estudos em torno do case management se iniciaram nos Estados Unidos ${ }^{1}$ em meados de 1970 com o projeto Judicial Case Management ${ }^{2}$, e hoje já diversos ordenamentos jurídicos ${ }^{3}$, tanto da civil law quanto da common law, tornando-se, portanto, uma tendência mundial.

Com efeito, o poder de gerenciamento do processo pelo juiz como forma de melhorar a qualidade da justiça ${ }^{4}$, vem sendo gradativamente adotado Inglaterra, ${ }^{5}$ França ${ }^{6}{ }^{7}$ Alemanha, ${ }^{8}$ Portugal $^{9}$ e Itália. ${ }^{10}$

As discussões inicialmente travadas na doutrina nacional ${ }^{11}$ e estrangeira ${ }^{12}$ giravam em torno do privatismo e do publicismo no processo civil, ou seja, se o sistema deveria prestigiar mais a atuação das partes (adversarial) ou do juiz (inquisitorial) dentro do processo. Atualmente esse debate ficou ultrapassado, pois o formato ideal de processo civil exige a cooperação de todos os players (juiz, partes e advogados), com o propósito final de alcançar resultados mais justos, céleres e eficientes..$^{13}$

No Brasil, o aumento dos poderes do juiz tem sido objeto de discussão desde o início do século passado, passando por diversas fases até chegar ao estágio atual ${ }^{14}$. Desde o $\mathrm{CPC} / 73$, já tínhamos um sistema processual que conferia amplos poderes ao juiz, especialmente no campo probatório. $\mathrm{O}$ CPC/ 15 ampliou ainda mais essa postura ativa do magistrado, mas também trouxe técnicas capazes de garantir maior participação das partes na condução do procedimento, proporcionando mais harmonia e equilíbrio entre os sujeitos processuais.

1 Sobre o assunto: RESNIK, Judith. Managerial Judges. Harvard Law Review, v. 96, n. 2, p. 374-448, Dec. 1982. Disponível em: <http:/ / www.jstor.org/pss/1340797>. Acesso em: 14 jan. 2008.

2 GAJARDONI, Fernando. Gestão de conflitos nos Estados Unidos e no Brasil. Revista Eletrônica de Direito Processual REDP. Ano 12. Vol. 19. № 3. Rio de Janeiro. Setembro a Dezembro de 2018. pp. 276-295, p. 282.

3 Destaca Michele Taruffo que na maioria dos ordenamentos jurídicos comparados há tendência em fortalecer de forma simultânea e com total compatibilidade os poderes do juiz e os direitos processuais dos jurisdicionados. In: TARUFFO, Michele. Investigación judicial y producción de prueba por las partes. Traducción de Juan Andrés Varas Braun. Revista de Derecho. Valdivia, v. 15, n. 2, dez. 2003, p. 205.

4 Acerca das novas tendências mundiais, cf.: CHASE, Oscar G.; HERSHKOFF, Helen (Eds.), Civil litigation in comparative context. St. Paul: Thomson/West, 2007, p. 241-260.

5 Sobre o assunto: BARBOSA MOREIRA, José Carlos. Uma novidade: o Código de Processo Civil inglês. Revista de Processo. São Paulo: Revista dos Tribunais, ano 25, n. 99, jul./set., 2000, p. 74-83. Ainda sobre o tema, cf. ANDREWS, Neil. O moderno processo civil: formas judiciais e alternativas de resolução de conflitos na Inglaterra. Orientação e revisão da tradução: Teresa Arruda Alvim Wambier. São Paulo: Revista dos Tribunais, 2009.

6 Interessantes considerações sobre o ordenamento jurídico francês, retratando as perspectivas do futuro, podem ser encontradas em: PERROT, Roger. O processo civil francês na véspera do século XXI. Tradução de José Carlos Barbosa Moreira. Revista de Processo. São Paulo: Revista dos Tribunais, ano 23, n. 91, jul./set., 2000, p. $203-212$.

7 Cf.: CADIET, Loïc. Conventions relatives au process en droit français. Revista de Processo. São Paulo: Revista dos Tribunais, ano 33, n. 160, jun., 2008, p. 61-82.

8 Sobre a reforma, ver os textos de José Carlos Barbosa Moreira: Breve notícia sobre a reforma do processo civil alemão. Revista de Processo. São Paulo: Revista dos Tribunais, ano 28, n. 111, jul./set., 2003, p. 103-112; e Temas de direito processual: nona série. São Paulo: Saraiva, 2007, p. 39-54.

9 Cf. FARIA, Paulo Ramos de. Regime processual civil experimental comentado. Coimbra: Almedina, 2010.

10 COMOGLIO, Luigi Paolo; FERRI, Conrado; TARUFFO, Michele. Lezioni sul processo civile. Bolonha: Il Mulino, 1995, p. 395-396.

11 BARBOSA MOREIRA, José Carlos. A função social do processo civil moderno e o papel do juiz e das partes na direção e na instrução do processo. Temas de direito processual: terceira série. São Paulo: Saraiva, 1984, p. 53-56.

12 Toda discussão é tratada na obra: MONTERO AROCA, Juan (Coord.). Proceso civil e ideología: un prefacio, una sentencia, dos cartas y quince ensayos. Valencia: Tirant lo Blanch, 2006.

13 Esta conclusão está inserida no recente Relatório da ELI-UNIDROIT, que objetiva consolidar as Regras Europeias de Processo Civil, ainda não disponível, mas que foi apresentado no Curso de Verão promovido pela Universidade do Espírito Santo em fevereiro de 2020, que contou com a participação de Professores que integram os Grupos de Trabalho (http: $/ /$ www.direito.ufes.br/sites/direito.ufes.br/files/field/anexo/cartaz ss.pdf). Acesso em 25 jun. 2020.

14 Sobre a evolução dos poderes do juiz, cf.: AMENDOEIRA JUNIOR, Sidney. Poderes do juiz e tutela jurisdicional: a utilização racional dos poderes do juiz como forma de obtenção da tutela jurisdicional efetiva, justa e tempestiva. São Paulo: Atlas, 2006. p. 38-48. 
O gerenciamento do processo pelo juiz em busca de resultados mais encontra respaldo na Constituição Federal, especialmente no art. 5o incisos: XXXV ("a lei não excluirá da apreciação do Poder Judiciário lesão ou ameaça a direito"); LIV ("ninguém será privado da liberdade ou de seus bens sem o devido processo legal”); e LXXVIII ("a todos, no âmbito judicial e administrativo, são assegurados a razoável duração do processo e os meios que garantam a celeridade de sua tramitação”).

No CPC/15, todos os doze dispositivos inseridos nas normas fundamentais do processo civil conferem, em algum grau, autorização para a gestão processual, com a finalidade de alcançar uma prestação jurisdicional que seja proporcional e efetiva.

Registre-se que o gerenciamento da marcha processual do juiz não se confunde com a ideia pejorativa de ativismo judicial, quando a discricionariedade do julgador fere direitos fundamentais ou garantias processuais, podendo, ainda, invadir outras esferas de Poder. ${ }^{15}$

Ao contrário, o poder diretivo do juiz proporcionado pelo caso management é aquele amparado em técnicas previstas pelo legislador, que busca compatibilizar de modo responsável e proporcional o procedimento às particularidades do caso concreto, tratando-se, pois, de uma condução processual vinculada à lei.

Não obstante, sabe-se que o CPC/15 também ampliou as formas de atuação das partes no processo, inclusive para a modulação de procedimento, como por meio das convenções processuais (art. 190). Porém, o protagonismo diretivo do juiz se destaca por envolver outras atividades gerenciais, que incluem importantes ações administrativas e judiciais. ${ }^{16}$

Saliente-se, ainda, que essa postura ativa do juiz foi temperada pelo legislador com a exigência ampliada de cooperação entre os sujeitos processuais, de observância do contraditório, e da presença da boa-fé no comportamento de todos os envolvidos ${ }^{17}$. Assim, esses três elementos (cooperação, contraditório e boa-fé) legitimam o poder gerencial do juiz.

Portanto, o presente estudo objetiva analisar as formas, as técnicas e os requisitos do case management no sistema processual brasileiro.

\section{Formas de gerenciamento do processo}

O papel gerencial do juiz contempla diversas atividades e iniciativas que são essenciais para a eficiência da prestação jurisdicional, sendo que a doutrina possui classificações distintas para o fenômeno.

No direito estrangeiro, Anna Nylund, Professora da Universidade de Thomso (Noruega), entende que o case management pode ter três aspectos: a) gerencial, relativo à organização do trabalho, incluindo a atribuição do caso ao juiz apropriado; b) processual, se refere à administração do tempo para cada caso e à adaptação do procedimento em si; e c) substancial, em que o juiz ajuda as partes a identificar o escopo do caso antes da audiência principal para garantir que apresentem provas relevantes sobre as questões de fato e de direito. ${ }^{18}$

15 Sobre o assunto, cf.: GOMES, Gustavo Gonçalves. Juiz ativista x juiz ativo: uma diferenciação necessária no âmbito do processo constitucional moderno. In: DIDIER JR., Fredie; NALINI, José renato; RAMOS, Glauco Gumerato; LEVY, Wilson. Ativismo judicial e garantismo processual. Salvador: JusPODIVM, 2013, p. 287-302.

16 Em importante obra sobre o tema, Cláudia Schwerz registra com precisão que: "O gerenciamento do processo inserese em um universo maior, que contempla temas ligados a políticas públicas, gestão de cartórios judiciais, investimento na informatização dos processos, estrutura física dos cartórios, treinamento constantes dos funcionários públicos, atualização permanente do juiz, entre outras.”. CAHALI, Cláudia Elisabete Schwerz. O gerenciamento de processos judiciais: em busca da efetividade da prestação jurisdicional (com remissões ao projeto do novo CPC). Brasília: Gazeta Jurídica, 2013. (Coleção Andrea Proto Pisani, vol. 10), p. 32.

17 A lealdade processual também é exigida juiz. Sobre o tema, cf.: FARIA, Márcio Carvalho. A lealdade processual na prestação jurisdicional: em busca de um modelo de juiz leal. São Paulo: Revista dos Tribunais, 2017.

18 NYLUND, Anna. Case management in a comparative perspective: regulation, principles and practice. Revista de Processo. Vol. 292/2019, p. 377 - 395. Jun /2019. 
No Brasil, Erico Andrade defende que o case management pode ser concretizado por três formas: a) flexibilização processual, com mudança na estruturação dos procedimentos judiciais; b) criação do calendário do processo; e c) "contratualização" do processo. ${ }^{19}$

Já Cláudia Schwertz assevera que as principais ferramentas da gestão processual seriam: a) racionalização dos serviços por meio de técnicas que promovam a eficiência e a efetividade da marcha processual; b) flexibilização do procedimento; c) uso de meios adequados de solução de conflitos em conjunto com a solução judicial ou com a exclusão desta. ${ }^{20}$

Todas as classificações mencionadas são válidas, mas para este estudo, considera-se que o case management no sistema brasileiro teria como principais aspectos: a) gestão administrativa; b) gestão do conflito; e c) gestão do procedimento.

Passa-se, então, à análise das particularidades de cada uma dessas dimensões.

\subsection{Gestão administrativa}

A gestão administrativa do juiz é pouco explorada na doutrina processual, mas representa relevante impacto na eficiência do nosso Poder Judiciário. Isso porque o gerenciamento do processo pelo juiz, por si só, não é capaz de afastar gargalos da Justiça: custo-lentidão-complexidade.

Assim, o modelo contemporâneo de atuação judicial exige novas práticas judiciárias e judiciais, de modo que, além do dever de assimilar e aplicar corretamente as técnicas processuais instituídas pelo $\mathrm{CPC} / 15$, ao juiz moderno é exigido um comportamento administrativo eficaz, sem o qual não seria possível oferecer efetividade na prestação jurisdicional.

Nesse contexto, fora os aspectos processuais, o gerenciamento do magistrado deve incluir aspectos periféricos à atividade jurisdicional em si, relacionados à estrutura administrativa, pessoal e material da unidade judiciária, uma vez que podem influenciar no bom andamento do processo e prejudicar a eficiência do sistema judiciário.

Denomina-se governança o mecanismo analítico de compreensão e controle dos fatores que envolvem todos os meios pessoais, materiais e estruturais no alcance dos objetivos ${ }^{21}$. Por conseguinte, a gestão judicial é o conjunto de tarefas que garante o uso eficaz de recursos do Poder Judiciário visando uma atuação mais adequada.

O modelo de juiz-gestor constitui um novo paradigma, pois otimiza o funcionamento das unidades judiciárias, utilizando indicadores e metas de desempenho no exercício de sua profissão. Planos estratégicos e operacionais, bem como um efetivo acompanhamento e controle de gestão garantem a qualidade na entrega da prestação jurisdicional, especialmente em unidades judiciárias doentes. ${ }^{22}$

A governança judicial ganhou força no Brasil especialmente após a criação do Conselho Nacional de Justiça - CNJ, que tem por missão servir de instrumento efetivo de desenvolvimento do Poder Judiciário, contribuindo para a efetividade dos trabalhos judiciários.

Para esse fim, o CNJ utiliza a Gestão de Processos como metodologia para acompanhar, avaliar e redesenhar os processos de trabalho, visando à melhoria contínua destes e o alcance dos objetivos

19 ANDRADE, Érico. As novas perspectivas do gerenciamento e da "contratualização" do processo. Revista de Processo, vol. $193 / 201$, p. 167 - 200, Mar/2011.

20 CAHALI, Cláudia Elisabete Schwerz. O gerenciamento de processos judiciais: em busca da efetividade da prestação jurisdicional (com remissões ao projeto do novo CPC). Brasília: Gazeta Jurídica, 2013. (Coleção Andrea Proto Pisani, vol. $10)$, p. 45 .

21 AKUTSU, Luiz; GUIMARÃES, Tomas de Aquino. Dimensões da governança judicial e sua aplicação ao sistema judicial brasileiro. Disponível em: < http://www.scielo.br/scielo.php?pid=S1808-24322012000100008\&script=sci arttext >. Acesso em: 07 jan. 2015.

22 REIS, Wanderlei José dos. Juiz-gestor: um novo paradigma. Disponível em: http://www.ibrajus.org.br/revista/ artigo.asp?idArtigo=215. Acesso em: 07 jan. 2015. 
estratégicos da organização. A cada ano são estipuladas metas de desempenho que devem ser cumpridas pelas unidades judiciárias.

Dessa forma, compete ao juiz realizar o controle e o cumprimento dessas metas e, para tanto, depende de forma direta do compromisso de todos os que integram a equipe de trabalho, como assessores, servidores, estagiários, e outros auxiliares da justiça.

Com isso, cria-se um novo desafio, que é fazer com que os servidores entendam a atual filosofia e aceitem caminhar em direção a um objetivo comum, que é gerir uma unidade judiciaria de forma correta e dinâmica.

Somente para exemplificar, a gestão administrativa do juiz inclui: controlar número de processos que ingressam na unidade; controlar o número de sentenças, que deve ser superior ao número de demandas ajuizadas; fiscalizar a correta classificação dos processos no sistema (taxonomia); garantir a limpeza e organização do cartório e do gabinete; verificar se a estrutura material e pessoal atende à vara; realizar relatórios de produtividade e de correições, bem como responder ofícios; fiscalizar a produtividade de estagiários e servidores; entre inúmeras outras atribuições.

Atualmente também ganhou destaque a gestão do uso da tecnologia, para o incremento de automação de tarefas e realização de atos virtuais.

O CPC/15, reconhecendo a necessidade de gerenciamento administrativo do juiz e a importância do papel do CNJ, previu em alguns dispositivos o auxílio do referido órgão, como no art. 196, que trata da regulamentação da prática e comunicação oficial de atos eletrônicos, velando pela compatibilidade dos sistemas, e no art. 1.069, que dispões sobre a realização de pesquisas estatísticas para avaliação da efetividade.

O Código também disciplinou no art. 12 a exigência de o juiz seguir a ordem cronológica de conclusão dos processos para o seu julgamento, dando-se, inclusive, publicidade às listas formadas. Ainda de acordo a referida regra, se o processo da listagem precisar sair para instrução ou diligência, volta depois para a mesma posição. Por sua vez, se a sentença for anulada ou na hipótese do 1.040, II, o feito retorna para o $1^{0}$ lugar na lista.

Pelo referido dispositivo, na prática, o magistrado teria que formar ao todo nove blocos de processos: a) sentenças comuns; b) sentenças proferidas em audiência, homologatórias de acordo e de improcedência liminar; c) casos repetitivos; d) sentenças do 485 e 932; e) embargos de declaração; f) preferências legais do CNJ; g) processos criminais; e h) causas urgentes, assim consideradas de forma fundamentada.

Por sua vez, art. 153 estabelece que "o escrivão ou chefe de secretaria deverá obedecer à ordem cronológica de recebimento para publicação e efetivação dos pronunciamentos judiciais”, sob pena de responsabilidade funcional. ${ }^{23}$

Observa-se, pois, que o CPC/2015, se aplicado ao pé da letra, poderia acabar comprometendo a gestão de processos feita pelo juiz e pelos tribunais, tanto em relação à gestão das unidades judiciais pelos auxiliares da justiça, quanto no que se refere à ordem de julgamento dos processos.

Por essa razão o artigo foi fortemente criticando pela comunidade jurídica, uma vez que retira do juiz e dos servidores a liberdade de administração das unidades judiciárias por meio da aplicação de outras técnicas de gestão em nome da igualdade de tratamento pelo Poder Judiciário.

Diante disso, o dispositivo foi alterado pela Lei $n^{0}$ 13.256/2016, e a imperatividade do texto foi substituído pela expressão "preferencialmente", amenizando sobremaneira a ideia originária do legislador que era provocar uma mudança comportamental.

23 GAJARDONI: Fernando. O novo CPC e o fim da gestão na Justiça. Disponível em: < http: $/ /$ jota.info $/$ o-novo-cpce-o-fim-da-gestao-na-justica >. Acesso em 20 fev. 2015. 
De qualquer modo, resta evidente que somente o empenho processual do juiz não é suficiente para garantir uma tutela jurisdicional satisfatória. A gestão administrativa (judiciária) aliada à judicial, é muito mais eficaz na garantia da coerência estrutural do sistema de justiça.

A gestão administrativa consome grande parte do tempo e da energia dos magistrados, e por isso devem ser considerados na equação da eficiência do Poder Judiciário.

Portanto, constata-se que a maior qualidade na gestão administrativa e na condução processual pode proporcionar a efetividade jurisdicional ${ }^{24}$, eliminando, por consequência, a morosidade das ações judiciais e a baixa eficácia de suas decisões.

\subsection{Gestão do conflito}

Tema que se torna cada vez mais relevante no cenário nacional, a gestão do conflito implica em o juiz identificar e compreender o tipo de relação jurídica material e processual em que as partes estão inseridas, o que terá reflexos na condução do processo com um todo.

Inicialmente, é importante que o juiz verifique os seguintes aspectos: a) se a relação entre as partes é de natureza continuada ou se não há vínculo anterior entre as partes; b) se o direito discutido admite autocomposição; c) se as partes já tentaram eliminar o conflito por meio de um acordo antes da judicialização; e d) se o conflito possui um grau de complexidade e especialidade a se compatibilizar com outros métodos de resolução de conflitos.

O gerenciamento do conflito tem início logo no juízo de admissibilidade da petição inicial, e pode ocorrer em diversos momentos do procedimento. Assim, quando o juiz realiza a triagem dos processos e analisa a inicial já é possível identificar os principais contornos da relação jurídica nos planos material e processual.

Em outros termos, o juiz deve considerar os elementos objetivos (direito material) e subjetivos (pessoas envolvidas no conflito) que permeiam a relação jurídica processual.

Isso permite que o juiz direcione o processo para o método adequado, atendendo ao que preconiza o art. $3^{\circ}$, do CPC, inserido nas normas fundamentais do processo civil. O referido dispositivo trata da inafastabilidade do Poder Judiciário, mas também autoriza o uso da arbitragem, e ainda estabelece de forma contundente a preferência pelas formas consensuais de resolução de conflito.

Nesse contexto, pode-se afirmar que o CPC contempla a ideia de Justiça Multiportas ${ }^{25}$, cuja evolução teve por base legislativa especialmente a Resolução no 125/2010, do CNJ, a Lei nº 13.140/2015 (Lei de Mediação) e a Lei nº 9.307/96 (Lei de Arbitragem).

Essa sustemática traz uma nova perspectiva ideológica e comportamental para o processo civil, já que imprime a necessidade de adequar o conflito ao método que seja mais compatível para o seu tratamento. Trata-se de um novo dever de adequação e consensualidade que deve ser exigido do Estado e de todos os sujeitos processuais.

Para dar concretude a esse dever, o CPC instituiu audiências de conciliação ou mediação no início do procedimento comum (art. 334) e em alguns procedimentos especiais (ações de família e litígio coletivo de posse de imóvel).

Assim, o juiz, ao apreciar a petição inicial, deverá verificar se o direito admite autocomposição. Em caso positivo, dependendo da complexidade do conflito, o juiz analisaria se seria o caso de encaminhar

24 Cf.: CAHALI, Cláudia Elisabete Schwerz. O gerenciamento de processos judiciais: em busca da efetividade da prestação jurisdicional (com remissões ao projeto do novo CPC). Brasília: Gazeta Jurídica, 2013. (Coleção Andrea Proto Pisani, vol. $10)$.

25 ZANETI JR., Hermes; CABRAL, Trícia Navarro Xavier. Justiça Multiportas: mediação, conciliação, arbitragem e outros meios de solução adequada de conflitos. (Coleção Grandes Temas do Novo CPC - vol. 9). 2a ed. revista, ampliada e atualizada. Salvador: JusPODIVM, 2018. 
o caso para uma audiência de mediação (relações mais complexas, de trato continuado) ou para uma de conciliação (relações mais simples e pontuais).

Registra-se que a designação da audiência inaugural do art. 334, do CPC, é cogente para o juiz, só podendo ser dispensada se ambas as partes manifestem desinteresse no ato ou se o direito não comportar autocomposição. Ademais, caso as partes comprovem satisfatoriamente que já tentaram construir uma solução consensual extrajudicialmente, o juiz poderá dispensar a audiência inicial.

Não obstante, dependendo do grau de complexidade e especialidade do conflito, bem como da necessidade de uma produção probatória cara e mais elaborada, nada impede que o juiz pondere - e não determine - com as partes sobre o uso da arbitragem, sem que isso constitua qualquer abdicação de sua jurisdição.

Existem, ainda, outros métodos de solução consensual de conflitos como a própria negociação direta. Já há algumas decisões de tribunais brasileiros suspendendo o processo de natureza consumerista para que o autor utilize plataformas on-line de resolução de disputas, sob pena de extinção do feito sem resolução sem mérito por falta de interesse de agir. Entretanto, trata-se de discussão que foge ao contexto deste estudo.

Nota-se, pois, que a imagem do juiz descompromissado com a melhor solução do conflito não pode subsistir. Mais do que dirigir formalmente o processo, o juiz deve imprimir maior proximidade com a resolução substancial do feito.

\subsection{Gestão do procedimento}

A gestão do procedimento ${ }^{26}$ deve ser entendida como a possibilidade de o juiz realizar adaptações procedimentais e aplicar técnicas processuais que melhor se ajustem às particularidades do caso concreto, propiciando adequação, rendimento, eficiência e racionalidade à entrega da prestação jurisdicional. ${ }^{27}$

O CPC traz inúmeras hipóteses de adaptação do procedimento, em especial no art. 139, que traz um rol de poderes, deveres e responsabilidade do juiz, indicando diferentes formas de gestão do processo pelo juiz. O dispositivo é mais amplo do que o art. 125, do CPC/73, estabelecendo os poderes de direção do juiz e imputando-lhe a incumbência de: a) zelar pela igualdade; b) garantir a duração razoável do processo; c) prevenir ato atentatório à dignidade da justiça e procrastinatórios; d) determinar medidas coercitivas para assegurar a obtenção da tutela de direito; e) promover a autocomposição; f) adequar o procedimento dilatando prazos e alterando ordem de produção dos meios de prova; g) exercer poder de polícia; h) determinar o comparecimento pessoal das partes para inquirição; i) controlar os defeitos processuais; e j) atentar para as demandas individuais repetitivas.

Verifica-se que o referido dispositivo legal acrescentou cinco novas hipóteses de atuação do magistrado, sendo três delas de bastante relevância para garantir a adequada gestão processual, constantes dos seguintes incisos: a) IV - determinar todas as medidas indutivas, coercitivas, mandamentais ou subrogatórias necessárias para assegurar o cumprimento de ordem judicial, inclusive nas ações que tenham por objeto prestação pecuniária; b) VI - dilatar os prazos processuais e alterar a ordem de produção dos meios de prova, adequando-os às necessidades do conflito de modo a conferir maior efetividade à tutela do direito; e c) IX - determinar o suprimento de pressupostos processuais e o saneamento de outros vícios processuais;

Na realidade, o Código em vigor prevê variadas espécies de adaptação do procedimento, conferindo bastante flexibilidade aos sujeitos processuais, especialmente ao juiz, que pode modular os atos e o procedimento.

26 Tratando a jurisdição como estrutura de governança judicial, cf.: CORRÊA, Fábio Peixinho Gomes. Governança judicial. São Paulo: Quartier Latin, 2012.

27 Segundo Barbosa Moreira, os poderes do juiz servem de instrumento para a boa prestação jurisdicional, mas é a quantidade e a qualidade de sua atuação que dirão se contribuíram para a efetividade do processo, objetivo de toda reforma. BARBOSA MOREIRA, José Carlos. Reformas processuais e poderes do juiz. Revista da EMERJ, v. 6, n. $22,2003$. 
Nesse contexto, seriam cinco as principais formas de gerenciamento procedimental pelo juiz:

i) controle da regularidade do processo: compete ao juiz, desde o recebimento da petição inicial, ao realizar ojuízo de admissibilidade, verificar a existência de defeitos processuais capazes de comprometer o procedimento, primando para que o processo se desenvolva de modo adequado.

Assim, a cada ato e fase processual o juiz deve conferir a presença dos requisitos previstos em lei, e, identificada eventual ausência, determinar que seja sanado pela parte. Esse controle precoce das irregularidades evita que haja retrocessos no futuro, com o reconhecimento de invalidades de atos capazes de comprometer todo o trabalho até então desenvolvido.

A garantia da ordem pública processual ${ }^{28}$ pelo juiz é fundamental para legitimar o procedimento e conferir segurança jurídica aos jurisdicionados.

E uma vez identificado algum defeito processual, deve o juiz lançar mão do princípio da sanabilidade, aproveitando os atos praticados, desde que atinjam a sua finalidade e não acarretem prejuízos às partes, nos termos do art. 283, do CPC.

ii) garantia de cumprimento de das decisões judiciais: o art. 199, IV, autoriza o juiz a determinar todas as medidas indutivas, coercitivas, mandamentais ou sub-rogatórias necessárias para assegurar o cumprimento de ordem judicial, inclusive nas ações que tenham por objeto prestação pecuniária. ${ }^{29}$

Como se vê, o dispositivo prevê deferentes espécies de comandos judiciais para efetivar e satisfazer a ordem judicial. Importante esclarecer que por "ordem judicial" deve se entender por qualquer tipo de pronunciamento judicial, seja decisão, sentença ou acórdão.

Diante disso, começaram a surgir decisões em que, diante do inadimplemento do executado de obrigação de pagar quantia certa, fora determinada a suspensão da Carteira Nacional de Habilitação, a apreensão do passaporte do devedor e o cancelamento dos cartões de crédito do executado, até o pagamento da dívida.

A doutrina reagiu imediatamente. De um lado, houve quem reconhecesse que a adoção da atipicidade das medidas executivas também nas execuções de obrigação de pagar quantia ensejou uma nova sistemática executiva, representando inclusive o que se denominou de uma "revolução silenciosa da execução por quantia”, embora critérios como excepcionalidade, proporcionalidade, fundamentação, menor onerosidade para o executado e respeito aos direitos e garantias fundamentais devam ser considerados pelo juiz ${ }^{30}$. De outra banda, há posicionamento doutrinário que reputa o dispositivo uma "carta branca para o arbítrio" "' de direitos fundamentais, descontextualizadas das premissas constitucionais.

Ao nosso sentir, com razão as duas correntes. Explica-se. Uma das justificativas do legislador para a instituição da reforma processual foi a necessidade de redefinição ideológica do CPC, conformando-o aos valores da Constituição de 1988, consolidando, assim, um modelo constitucional do processo.

E no capítulo que trata das normas fundamentais do processo civil, restou estabelecido no art. $4^{\text {o }}$ que as partes têm o direito de obter em prazo razoável a resolução do mérito e sua satisfação. Em outros termos, prevê o dispositivo que os direitos devem ser reconhecidos e também efetivados. Esta norma fundamental deve guiar os sujeitos processuais, mas em especial o magistrado, em toda sua atuação,

28 Sobre o tema, cf.: CABRAL, Trícia Navarro Xavier. Ordem pública processual. Brasília: Gazeta Jurídica, 2015.

29 Acerca do assunto, cf.: CABRAL, Trícia Navarro Xavier.As novas tendências da atuação judicial. In: TALAMINI, Eduardo; MINAMI, Marcos Youji. Medias executivas atípicas (Coleção Grandes Temas do Novo CPC). 2ª ed. Revista e atualizada. Salvador: JusPODIVM, 2020. p. 611-628.

30 Sobre o tema, conferir: GAJARDONI, Fernando: A revolução silenciosa da execução por quantia. Disponível em: $\underline{\text { http: } / /}$ jota.uol.com.br/a-revolucao-silenciosa-da-execucao-por-quantia. Acesso em 02/09/2016.

31 Ver: STRECK, Lênio; NUNES, Dierle. Como interpretar o art. 139, IV, do CPC? Carta branca para o arbítrio? Disponível em: http://www.conjur.com.br/2016-ago-25/senso-incomum-interpretar-art-139-iv-cpc-carta-branca-arbitrio. Acesso em $30 / 08 / 2016$. 
quebrando a dicotomia cognição x execução, a fim de que os dois momentos sejam considerados sob a premissa única da finalidade ou do resultado final pretendido.

Sob outro prisma, com o estabelecimento de uma parte geral aplicável a todos os institutos processuais, não há dúvidas de que os preceitos envolvendo os poderes do juiz podem ser aplicáveis também à execução, de forma inclusive cumulativa com as previsões específicas relativas a esta última.

E ao transportar essas perspectivas para a efetivação das decisões judiciais, alteram-se por completo as expectativas executivas no tocante ao poder de atuação do magistrado, às possibilidades do credor de quantia - antes dependente dos meios tradicionais de coerção do executado para a satisfação de seu crédito -, bem como se põe em cheque a interpretação sobre o princípio da menor onerosidade do devedor.

Tem-se, pois, uma cláusula geral de efetivação das ordens judiciais, inclusive no que concerne ao processo de execução ou cumprimento de sentença. Importante contextualizar que, entre as inúmeras alterações do CPC/15, o processo de execução foi o que menos sofreu modificação, embora tenha havido aperfeiçoamentos pontuais. Isso porque as reformas processuais de 2005 (Lei n. 11.232/05) e 2006 (Lei n. 11.382/06) já haviam tratado dos principais aspectos da sistemática executiva, muitas delas ainda em estágio de assimilação pela comunidade jurídica.

Assim, o CPC/15 empenhou esforços a fim de melhorar aspectos processuais já bastante ultrapassados, de acordo com a evolução da doutrina e jurisprudência, bem como pelo advento da Constituição da República de 1988, mas procurou respeitar a solidificação de modificações legislativas ainda em processos de amadurecimento, como foi caso da reforma processual relativa à execução.

Contudo, a potencialidade inserta no art. 139 acabou por, indiretamente, reforçar sobremaneira as medidas executivas típicas, prevendo medidas coercitivas e indutivas de execução indireta também para efetivar ordem de pagamento. Em outros termos, a atipicidade das medidas executivas passou a ser aplicável também à persecução de obrigação de pagar quantia.

Ao tratar do assunto, Marcelo Abelha distingue com muita propriedade as medidas processuais punitivas das medidas processuais coercitivas, ambas aplicáveis ao executado, por meio de um "duplo dever do magistrado". As primeiras, aplicáveis às situações que atentem ao dever de lealdade e boa-fé estariam previstas no inciso III, do art. 139, e as segundas, destinadas à promoção das ordens judiciais, se enquadrariam no inciso IV, do mesmo dispositivo legal.

Nesse contexto, diz o autor, se o comportamento do executado estiver voltado para atos de improbidade processual (arts. 77, IV e 774), aplica-se uma medida processual de caráter punitivo (art. 139, III). Porém, se a conduta do executado se relacionar ao descumprimento da ordem judicial, cabível se torna a aplicação de medidas processuais coercitivas ou sub-rogatórias (art. 139, IV), desde que adequadas, proporcionais e razoáveis para atingir sua finalidade.

De todo modo, as medidas processuais punitivas devem seguir o regime de tipicidade, pois ela é a própria consequência (fim), em contraposição à aplicação de medidas processuais coercitivas, que adotam o regime de atipicidade, sendo apenas um instrumento (meio) para o alcance do resultado pretendido, embora ambas possam ser cumuladas. ${ }^{32}$

Importante ressaltar, ainda, que para a aplicação de medidas atípicas, o juiz deve observar parâmetros valorativos constitucionais (art. $5^{\circ}, \mathrm{CF}$ ) e processuais (art. $8^{\circ}$, CPC) como atender aos fins sociais e às exigências do bem comum, a dignidade da pessoa humana, a legalidade, a razoabilidade e a proporcionalidade e a eficiência do processo.

Dessa forma, diante das premissas supracitadas, verifica-se que a atuação judicial em casos de descumprimento de suas ordens deve considerar dois fatores: a) o tipo de comportamento do executado, se de mero descumprimento de ordem judicial ou se de improbidade processual, ou se ambas as hipóteses;

32 Cf.: RODRIGUES, Marcelo Abelha. O que fazer quando o executado é um "cafajeste”? Apreensão de passaporte? Da carteira de motorista? Disponível em: http: / / www.migalhas.com.br/dePeso $/ 16, \mathrm{MI} 245946,51045-\mathrm{O}+\mathrm{que}^{+} \mathrm{fazer}+\mathrm{quando}+\mathrm{O}+\mathrm{execut}$

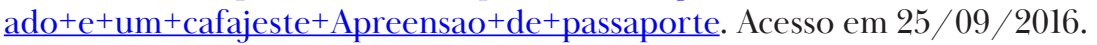


e b) a pertinência entre a situação fática e jurídica em questão e a medida adotada pelo juiz, evitando-se distorções que comprometam a finalidade da norma.

Ademais, importante também ressaltar a subsidiariedade e excepcionalidade que as medidas atípicas devem ter em relação às medidas típicas, que precisam ser esgotadas antes da aplicação daquelas. Não obstante, em caso de cumulação de medidas atípicas, para fins de constatação de sua adequação, elas devem ser consideradas tanto de modo isolado como conjuntamente. ${ }^{33}$

Assim, na hipótese específica de descumprimento de ordem judicial, caberiam medidas atípicas, como por exemplo: a dívida de veículos poderia ensejar a suspensão da $\mathrm{CNH}$; a dívida de alimentos poderia gerar a apreensão do passaporte para impedir viagens e gastos no exterior; a dívida de cartão de crédito poderia impedir o fornecimento de novas linhas de crédito ou de outros benefícios bancários. Mas cada uma dessas medidas deve ser exaustivamente fundamentada, demonstrando a coerência entre o suporte fático e a medida judicial, legitimando a restrição imposta.

Com efeito, liberdade e propriedade são valores caros para a nossa sociedade e só devem ser limitados diante de circunstâncias que justifiquem tamanha intervenção estatal.

E para além do aspecto envolvendo o alcance da satisfação do credor, quando se trata de cumprimento de decisões judiciais, deve-se considerar também o aspecto relativo à própria credibilidade do Poder Judiciário, garantindo, assim, a sua função social.

iii) flexibilização do procedimento ${ }^{34}$ : a variação do procedimento admite diferentes formatos, podendo ser classificada em quatro categorias: a) por imposição legal; b) por ato judicial; c) por ato conjunto das partes e do juiz; e d) por atos de disposição das partes.

A primeira - flexibilização por imposição legal - ocorre quando o próprio legislador identifica, de antemão, as hipóteses passíveis de alteração do procedimento para melhor atender às especificidades da causa, de acordo com as peculiaridades do direito material controvertido (ex: escolha do procedimento pelo autor).

Por sua vez, a flexibilização por ato do juiz pode ocorrer em duas situações: a) quando a lei fixa previamente alternativas ao magistrado, ficando a critério deste escolher o procedimento a seguir, citando-se como exemplo, o julgamento antecipado do mérito ou o julgamento monocrático dos recursos; e b) quando o juiz, em razão de seus próprios poderes diretivos e de gestão, tem a autonomia de adaptar o procedimento, mesmo na falta de previsão legislativa específica ${ }^{35}$, como acontece no caso dos direitos difusos e coletivos, nos procedimentos diferenciados, na fungibilidade entre procedimentos liquidatórios, na importação de técnicas processuais.

Ademais, a variação do procedimento também pode ocorrer por ato conjunto das partes e do juiz. É a hipótese do calendário processual inserido no art. 191, do CPC/2015, que permite que os sujeitos processuais preestabeleçam datas para a prática de seus atos, adequando o ritmo e a duração da demanda às especificidades do caso concreto.

Por último, tem-se a possibilidade de as partes firmarem uma convenção em matéria de processo, nos termos do art. 190, do CPC, para ajustá-lo às especificidades da causa e para dispor sobre seus ônus,

\footnotetext{
33 Nesse sentido, ver: RODOVALHO, Thiago. O necessário diálogo entre a doutrina e a jurisprudência na concretização da atipicidade dos meios executivos. Disponível em: http://jota.uol.com.br/o-necessario-dialogo-entre-doutrina-ejurisprudencia-na-concretizacao-da-atipicidade-dos-meios-executivos. Acesso em 24/09/2016.

34 Sobre a evolução do tema no Anteprojeto da reforma do CPC, cf.: CABRAL, Trícia Navarro Xavier Cabral. Flexibilização procedimental. Revista Eletrônica de Direito Processual - REDP. Volume VI. № 6. Periódico da Pós-Graduação Stricto Sensu em Direito Processual da UERJ. 2010, p. 135-164.

35 Enunciado 35 (Enfam). Além das situações em que a flexibilização do procedimento é autorizada pelo art. 139, VI, do CPC/2015, pode o juiz, de ofício, preservada a previsibilidade do rito, adaptá-lo às especificidades da causa, observadas as garantias fundamentais do processo. https://www.enfam.jus.br/wp-content/uploads/2015/09/ENUNCIADOSVERS\%c3\%830-DEFINITIVA-.pdf. Acesso em 9 de jul. de 2020.
} 
poderes, faculdades e deveres processuais, tanto extrajudicialmente quanto durante a tramitação do processo judicial. ${ }^{36}$

Registre-se que o nosso ordenamento processual já vinha admitindo a flexibilização por imposição legal e a por ato do juiz. Porém, a novidade surge em relação às duas outras espécies de flexibilização, ou seja, a por ato conjunto das partes e do juiz e a por atos de disposição das partes, estabelecidas nos artigos 190 e 191, do CPC/2015.

A adaptabilidade do procedimento pelo juiz representa um importante mecanismo de racionalização do procedimento, a fim de que não seja além nem aquém das necessidades do direito material discutido.

iv) saneamento do processo: se a causa não comportar a resolução antecipada do mérito, o procedimento adentra na fase saneadora. Trata-se de etapa importante para a otimização do procedimento.

Nela o juiz concentrará o foco no que de fato é relevante para as fases probatória e decisória, e, nos termos do art. 357, do CPC, deverá: I - resolver as questões processuais pendentes, se houver; II - delimitar as questões de fato sobre as quais recairá a atividade probatória, especificando os meios de prova admitidos; III - definir a distribuição do ônus da prova, observado o art. 373; IV - delimitar as questões de direito relevantes para a decisão do mérito; V - designar, se necessário, audiência de instrução e julgamento.

A decisão saneadora será, em regra, dada em gabinete, resolvendo as questões preliminares, fixando pontos controvertidos, definindo a distribuição do ônus da prova, deferindo provas e, se for o caso, designando audiência de instrução e julgamento (art. 357). Entretanto, se a matéria apresentar complexidade de fato ou de direito, o juiz poderá designar audiência de saneamento para, em cooperação com as partes, delimitar melhor as alegações (art. 357, § 3º $)$.

Registre-se que o $\$ 9^{\circ}$, do art. 357 estabelece que as pautas devem ser preparadas com um intervalo mínimo de 1 (uma) hora entre as audiências. Trata-se de mais uma regra que pretende interferir no planejamento da rotina de trabalho do juiz em benefício das partes.

Portanto, o saneamento do processo requer uma adequada gestão pelo juiz, proporcionando maior rendimento às etapas processuais subsequentes.

v) poderes instrutórios: o art. 370, do CPC, autoriza o juiz, de ofício ou a requerimento da parte, determinar as provas necessárias ao julgamento do mérito, bem como a indeferir, em decisão fundamentada, as diligências inúteis ou meramente protelatórias (parágrafo único).

Assim, de acordo com o art. 353, do CPC, cumpridas as providências preliminares ou não havendo necessidade delas, o juiz poderá realizar o julgamento, conforme o estado do processo. Se não for o caso de julgamento antecipado do mérito, o juiz inicia a fase de saneamento e organização do processo.

No caso de julgamento antecipado do mérito, ainda que as partes tenham requerido a produção prova, o juiz pode dispensá-la quando não houver necessidade ou quando o réu for revel e não houver requerimento de prova, nos termos do art. 355, do CPC.

Por sua vez, durante a fase de saneamento e organização do processo o juiz, ao delimitar os pontos controvertidos, poderá deferir as provas pertinentes e indeferir as que forem inúteis ou desnecessárias para a elucidação dos fatos, racionalizando a fase probatória.

Ademais, o gerenciamento probatório do juiz também inclui o momento de produção das provas. Com efeito, durante a oitiva de testemunhas, realização de perícia e realização de outros meios legais de prova, podem ocorrer inúmeras circunstâncias a ensejar a atuação judicial para garantir a regularidade da fase instrutória, como, por exemplo, na oitiva de testemunhas, em que há necessidade de controlar os casos de incapacidade, impedimento e suspeição (art. 447), bem como a ordem de inquirição (art. 456) e a veracidade do teor das declarações prestadas (art. 458).

36 Sobre os limites da liberdade processuais, cf.: CABRAL, Trícia Navarro Xavier Cabral. Limites da liberdade processual. Indaiatuba/SP: FOCO, 2019. 
Portanto, esses poderes instrutórios do juiz são essenciais para garantir a qualidade das provas, a duração razoável do processo e a eficiência da prestação jurisdicional.

\section{Requisitos do gerenciamento processual pelo juiz}

O amplo poder de gerenciamento do juiz, em seus diferentes aspectos, deverá atender a alguns requisitos, a fim de que seja justificável e tenha sua legitimidade reconhecida. ${ }^{37}$

Dessa forma, a aplicação do case management, em todos os seus aspectos, exige um juiz compromissado em adequar os atos e procedimentos às particularidades do caso concreto, garantindo maior proporcionalidade e eficiência para a demanda.

Ademais, o juiz deve assegurar a igualdade de tratamento entre as partes, zelando para que todos os sujeitos processuais tenham as mesmas oportunidades dentro do processo (art. 139, I).

Não obstante, é preciso assegurar, em todas as etapas e potenciais adaptações, a cooperação, a boa-fé, o contraditório e a ampla defesa das partes, e, ainda, evitar a prolação de decisões surpresa (art. $10)$.

Por sua vez, os poderes gerenciais do juiz devem ser proporcionais e devidamente fundamentados. Com efeito, o CPC impõe ao julgador a apreciação de todos os argumentos levantados no processo, sob pena de nulidade.

$\mathrm{O} \S 1^{\mathbf{o}}$, do artigo 489 estabeleceu requisitos objetivos para a fundamentação de qualquer decisão judicial (interlocutória, sentença ou acórdão) que são: a) abordar todas as questões de fato e de direito; b) explicar a indicação do ato normativo; c) explicar o motivo da aplicação de conceito jurídico indeterminado; d) evitar motivos genéricos ou padrão; e) enfrentar todos os argumentos capazes de influenciar a convicção do julgador; f) identificar fundamentos que adequem o caso ao enunciado de súmula ou precedente; g) mostrar a distinção ou a superação do entendimento ao deixar de aplicar enunciado de súmula ou jurisprudência alegada.

Já o $§ 2^{o}$ prevê que, em caso de colisão de normas, deve o juiz indicar o objeto e os critérios da ponderação, tanto para afastar quanto para acolher a norma. Por sua vez, o $\$ 3^{0}$ estabeleceu a boa-fé como critério de interpretação da decisão.

Verifica-se, pois, que o juiz terá o dever de formular uma fundamentação exaustiva para justificar seu ato decisório.

Portanto, o gerenciamento do processo demanda uma conduta responsável do julgador ${ }^{38}$, que deverá atender os requisitos supracitados para que sua postura ativa tenha a adequada legitimidade, afastando qualquer ideia de arbítrio.

37 J.J. Calmon de Passos, ao tratar do protagonismo do juiz, diz que ele deverá observar: a) vinculados à legalidade, especialmente a constitucional; b) adequadamente controlado - interna e externamente; b) satisfatoriamente fundamentado; e c) responsável e garantidor do máximo de segurança e coerência para sociedade. CALMON DE PASSOS, J.J. O magistrado, protagonista do processo jurisdicional? Revista Eletrônica de Direito do Estado (REDE) no 24 - outubro/novembro/dezembro de 2010, Salvador/BA. Disponível em: http://www.direitodoestado.com.br/codrevista.asp?cod=460. Acesso em 09 jul. 2020 .

38 "Cuidar da acentuação de poderes, no entanto, é cuidar também, e forçosamente, de acentuação da responsabilidade. Quem se investe de poderes responde pela omissão em exercê-los na medida necessária, e responde de igual modo pelo exercício abusivo ou simplesmente inepto.”. (BARBOSA MOREIRA, José Carlos, Temas de direito processual: quarta série. São Paulo: Saraiva, 1989, p. 51). 


\section{Conclusão}

O case managementé uma tendência em diversos ordenamentos jurídicos, e, no Brasil, tem ganhado um contorno amplo e completo. Isso porque o aumento poderes do juiz se revela como importe forma de promoção de um processo mais igualitário, justo e tempestivo.

O CPC/ 15 muniu o juiz de instrumentos que possibilitam decisões mais efetivas e com técnicas processuais para permitir a entrega de uma prestação jurisdicional compatível com os novos direitos, por meio de mecanismos cada vez mais eficientes, exigindo, ainda, um comportamento cooperativo entre os sujeitos processuais.

Nesse contexto, foram conferidos ao julgador deveres de gestão em diferentes dimensões: administrativa, conflitual e procedimental. O gerenciamento administrativo prevê que o magistrado deverá zelar para que as questões periféricas ao julgamento, relativas à condução da unidade judiciária, sejam tratadas de forma adequada. Já o gerenciamento do conflito indica que o juiz deve identificar e compreender os aspectos objetivos (direito material) e subjetivos (pessoas envolvidas), a fim de que possa direcionar a causa para a solução mais apropriada. Por sua vez, o gerenciamento do procedimento se relaciona com a adaptação de atos e do procedimento às particularidades do caso concreto, permitindo mais proporcionalidade e racionalidade no uso do processo.

Não obstante, o gerenciamento do processo pelo juiz exige a observância de requisitos, em especial o da fundamentação adequada, sem os quais sua decisão perde legitimidade,

O legislador também se preocupou com a responsabilidade do juiz, prevendo, no art. 143, circunstâncias passíveis de responsabilização civil e regressiva por perdas e danos.

Portanto imprescindível que a atuação judicial seja bem dimensionada, garantindo a entrega de uma efetiva tutela jurisdicional, e, acima de tudo, conferindo segurança jurídica e confiança legítima do jurisdicionado. Somente com uma adequada gestão administrativa e judicial pelo juiz será possível o alcance da credibilidade e da eficiência do Poder Judiciário.

\section{Referências}

AKUTSU, Luiz; GUIMARÃES, Tomas de Aquino. Dimensões da governança judicial e sua aplicação ao sistema judicial brasileiro. Disponível em: < http://www.scielo.br/scielo.php?pid=S1808-

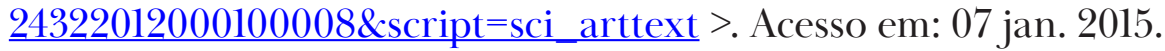

AMENDOEIRA JUNIOR, Sidney. Poderes do juiz e tutela jurisdicional: a utilização racional dos poderes do juiz como forma de obtenção da tutela jurisdicional efetiva, justa e tempestiva. São Paulo: Atlas, 2006.

ANDRADE, Érico. As novas perspectivas do gerenciamento e da "contratualização" do processo. Revista de Processo, vol. 193/201, p. 167 - 200, Mar/2011.

ANDREWS, Neil. O moderno processo civil: formas judiciais e alternativas de resolução de conflitos na Inglaterra. Orientação e revisão da tradução: Teresa Arruda Alvim Wambier. São Paulo: Revista dos Tribunais, 2009.

BARBOSA MOREIRA, José Carlos. Uma novidade: o Código de Processo Civil inglês. Revista de Processo. São Paulo: Revista dos Tribunais, ano 25, n. 99, jul./set., 2000, p. 74-83.

Breve notícia sobre a reforma do processo civil alemão. Revista de Processo. São Paulo: Revista dos Tribunais, ano 28, n. 111, jul./set., 2003, p. 103-112.

. Temas de direito processual: nona série. São Paulo: Saraiva, 2007, p. 39-54.

. Reformas processuais e poderes do juiz. Revista da EMERJ, v. 6, n. 22, 2003. 
. A função social do processo civil moderno e o papel do juiz e das partes na direção e na instrução do processo. Temas de direito processual: terceira série. São Paulo: Saraiva, 1984, p. 5356.

. Temas de direito processual: quarta série. São Paulo: Saraiva, 1989.

CABRAL, Trícia Navarro Xavier. Ordem pública processual. Brasília: Gazeta Jurídica, 2015.

. As novas tendências da atuação judicial. In: TALAMINI, Eduardo; MINAMI, Marcos Youji. Medias executivas atípicas (Coleção Grandes Temas do Novo CPC). 2ª ed. Revista e atualizada. Salvador: JusPODIVM, 2020. p. 611-628.

Flexibilização procedimental. Revista Eletrônica de Direito Processual - REDP. Volume VI. № 6 . Periódico da Pós-Graduação Stricto Sensu em Direito Processual da UERJ. 2010, p. 135-164.

Limites da liberdade processual. Indaiatuba/SP: FOCO, 2019.

CADIET, Loïc. Conventions relatives au process en droit français. Revista de Processo. São Paulo: Revista dos Tribunais, ano 33, n. 160, jun., 2008, p. 61-82.

CAHALI, Cláudia Elisabete Schwerz. O gerenciamento de processos judiciais: em busca da efetividade da prestação jurisdicional (com remissões ao projeto do novo CPC). Brasília: Gazeta Jurídica, 2013. (Coleção Andrea Proto Pisani, vol. 10).

CALMON DE PASSOS, J.J. O magistrado, protagonista do processo jurisdicional? Revista Eletrônica de Direito do Estado (REDE) no 24 - outubro/novembro/dezembro de 2010, Salvador/BA. Disponível em: http://www.direitodoestado.com.br/codrevista.asp?cod=460. Acesso em 09 jul. 2020.

CHASE, Oscar G.; HERSHKOFF, Helen (Eds.), Civil litigation in comparative context. St. Paul: Thomson/ West, 2007, p. 241-260.

COMOGLIO, Luigi Paolo; FERRI, Conrado; TARUFFO, Michele. Lezioni sul processo civile. Bolonha: Il Mulino, 1995, p. 395-396.

CORRÊEA, Fábio Peixinho Gomes. Governança judicial. São Paulo: Quartier Latin, 2012.

FARIA, Márcio Carvalho. A lealdade processual na prestação jurisdicional: em busca de um modelo de juiz leal. São Paulo: Revista dos Tribunais, 2017.

FARIA, Paulo Ramos de. Regime processual civil experimental comentado. Coimbra: Almedina, 2010.

GAJARDONI, Fernando. Gestão de conflitos nos Estados Unidos e no Brasil. Revista Eletrônica de Direito Processual - REDP. Ano 12. Volume 19. Número 3. Rio de Janeiro. Setembro a Dezembro de 2018. pp. 276-295.

GAJARDONI, Fernando: A revolução silenciosa da execução por quantia. Disponível em: http://jota. uol.com.br/a-revolucao-silenciosa-da-execucao-por-quantia. Acesso em 02 set. 2016.

. O novo CPC e o fim da gestão na Justiça. Disponível em: $<$ http://jota.info/o-novo-cpc-e-ofim-da-gestao-na-justica >. Acesso em 20 fev. 2015.

GOMES, Gustavo Gonçalves. Juiz ativista x juiz ativo: uma diferenciação necessária no âmbito do processo constitucional moderno. In: DIDIER JR., Fredie; NALINI, José renato; RAMOS, Glauco Gumerato; LEVY, Wilson. Ativismo judicial e garantismo processual. Salvador: JusPODIVM, 2013, p. 287-302.

MONTERO AROCA, Juan (Coord.). Proceso civil e ideología: un prefacio, una sentencia, dos cartas y quince ensayos. Valencia: Tirant lo Blanch, 2006.

NYLUND, Anna. Case management in a comparative perspective: regulation, principles and practice. Revista de Processo. Vol. 292/2019, p. 377 - 395. Jun /2019. 
PERROT, Roger. O processo civil francês na véspera do século XXI. Tradução de José Carlos Barbosa Moreira. Revista de Processo. São Paulo: Revista dos Tribunais, ano 23, n. 91, jul./set., 2000, p. 203-212.

REIS, Wanderlei José dos. Juiz-gestor: um novo paradigma. Disponível em: http://www.ibrajus.org.br/ revista/artigo.asp?idArtigo=215. Acesso em: 07 jan. 2015.

RESNIK, Judith. Managerial Judges. Harvard Law Review, v. 96, n. 2, p. 374-448, Dec. 1982. Disponível em: <http://www.jstor.org/pss/1340797>. Acesso em: 14 jan. 2008.

RODRIGUES, Marcelo Abelha. O que fazer quando o executado é um “cafajeste”? Apreensão de passaporte? Da carteira de motorista? Disponível em: http://www.migalhas.com.br/dePeso/16,MI245946,51045$\underline{\mathrm{O}+\text { que }^{+} \text {fazer }+ \text { quando }}+\mathrm{O}^{+}$executado $+\mathrm{e}^{+} \mathrm{um}^{+}$cafajeste + Apreensao $+\mathrm{de}^{+}$passaporte. Acesso em 25/09/2016.

RODOVALHO, Thiago. O necessário diálogo entre a doutrina e a jurisprudência na concretização da atipicidade dos meios executivos. Disponível em: http://jota.uol.com.br/o-necessario-dialogoentre-doutrina-e-jurisprudencia-na-concretizacao-da-atipicidade-dos-meios-executivos. Acesso em 24/09/2016.

STRECK, Lênio; NUNES, Dierle. Como interpretar o art. 199, IV, do CPC? Carta branca para o arbítrio? Disponível em: http://www.conjur.com.br/2016-ago-25/senso-incomum-interpretarart-139-iv-cpc-carta-branca-arbitrio. Acesso em 30/08/2016.

TARUFFO, Michele. Investigación judicial y producción de prueba por las partes. Traducción de Juan Andrés Varas Braun. Revista de Derecho. Valdivia, v. 15, n. 2, dez. 2003, p. 205.

ZANETI JR., Hermes; CABRAL, Trícia Navarro Xavier. Justiça Multiportas: mediação, conciliação, arbitragem e outros meios de solução adequada de conflitos. (Coleção Grandes Temas do Novo CPC - vol. 9). 2a ed. revista, ampliada e atualizada. Salvador: JusPODIVM, 2018. 